\title{
PENGEMBANGAN APLIKASI KRIPTOGRAFI FILE AUDIO \\ DENGAN ALGORITMA DATA ENCRYPTION STANDARD (DES)
}

\author{
I Wayan Dana Asmara, Made Windu Antara Kesiman, Ketut Agustini \\ Jurusan Pendidikan Teknik Informatika \\ Universitas Pendidikan Ganesha \\ email: dekndu@yahoo.com, eghee2006@gmail.com
}

\begin{abstract}
Data security is one important issue in the era of information technology and communications. One alternative of maintaining data security is to develop applications that implement cryptographic algorithms. This study aims to design and develop a cryptographic application that implements the algorithm of Data Encryption Standard (DES).

This application system is designed by using UML (Unified Modeling Language) with encryption and decryption of WAV files as the main design. Encryption and decryption process use the DES algorithm. DES algorithm is a symmetric cryptographic algorithms that uses the same key for encryption and decryption. DES algorithm takes part on 64 bit data blocks and uses a key length of 64 bits. The processes contained in the DES algorithm includes an internal key generation, the initial permutation, enchipering, and the final permutation.

Implementation of the DES algorithm in audio file cryptographic applications generate an software called a AudioEncryptor. Based on the results obtained by testing the software, AudioEncryptor is able to encrypt the audio files well. The voice that is produced by audio files different from actual sound, so the confidentiality of the information contained in audio files that are encrypted very securely. Besides encryption and decryption, AudioEncryptor also equipped by facilities to record and play the audio files. The software of AudioEncryptor is developed by using Java programming language in Java 2 Standard Edition (J2SE).
\end{abstract}

Key words: Cryptography, audio files, DES algorithm, WAV

\section{ABSTRAK}

Keamanan data merupakan salah satu isu penting di era teknologi informasi dan komunikasi. Salah satu alternatif untuk menjaga keamanan data adalah dengan mengembangkan aplikasi yang menerapkan algoritma kriptografi. Penelitian ini bertujuan 
untuk merancang dan mengembangkan sebuah aplikasi kriptografi yang mengimplementasikan algoritma Data Encryption Standard (DES).

Perancangan sistem aplikasi ini menggunakan UML (Unified Modeling Language) dengan enkripsi dan dekripsi file WAV sebagai rancangan utama. Proses enkripsi dan dekripsi ini menggunakan algoritma DES. Algoritma DES merupakan algoritma kriptografi simetri yaitu algoritma kriptografi yang menggunakan kunci yang sama untuk enkripsi dan dekripsi. Algortima DES bekerja pada blok data 64 bit dan menggunakan panjang kunci 64 bit. Proses-proses yang terdapat pada algoritma DES meliputi pembangkitan kunci internal, permutasi awal, enchipering, dan permutasi akhir.

Implementasi Algoritma DES pada aplikasi kriptografi file audio menghasilkan sebuah perangkat lunak yang disebut dengan AudioEncryptor. Berdasarkan hasil pengujian perangkat lunak diperoleh bahwa AudioEncryptor mampu mengenkripsi file audio dengan baik. Suara yang dikeluarkan file audio terenkripsi tidak sama dengan suara sebenarnya, sehingga kerahasiaan informasi yang terkandung dalam file audio yang sudah dienkripsi sangat aman. Selain enkripsi dan dekripsi, AudioEncryptor juga dilengkapi dengan fasilitas record dan play audio yaitu fasilitas untuk merekam dan memutar file audio. Perangkat Lunak AudioEncryptor sendiri dikembangkan dengan menggunakan bahasa pemrograman Java yaitu pada lingkungan Java 2 Standard Edition (J2SE).

Kata-kata kunci : Kriptografi, File audio, Algoritma DES, WAV

\section{PENDAHULUAN}

Teknologi informasi saat ini semakin populer digunakan dalam seluruh aspek kehidupan. Hampir seluruh informasi kini dikelola dalam bentuk digital. Hal ini didukung oleh berbagai keuntungan yang dapat diperoleh seperti kemudahan dalam penyimpanan dan kecepatan dalam pendistribusian. Akan tetapi, penggunaan data digital dalam mengelola pesan bukan berarti meningkatkan keamanan pesan tersebut. Berbagai teknik penyerangan telah muncul sehingga pihak yang tidak bertanggungjawab dapat mengetahui dan menyalahgunakan informasi rahasia yang terkandung dalam pesan. Oleh karena itu, faktor keamanan menjadi salah satu isu penting dalam pengelolaan data digital (Rasyid, 2009).

Kriptografi sebagai suatu ilmu hadir untuk meningkatkan aspek keamanan pesan. Hal ini dilakukan dengan menyandikan pesan ke dalam bentuk acak yang tidak dapat dimengerti lagi maknanya. Akan tetapi, dengan suatu algoritma dan kunci yang sudah ditentukan sebelumnya, bentuk acak tersebut dapat dikembalikan ke pesan semula.

Pengamanan data digital dengan kriptografi dapat diimplementasikan pada berbagai bentuk format data digital. Beberapa contohnya adalah implementasi kriptografi pada data teks, gambar, dan audio. Kriptografi pada data teks memang lebih familiar dikenal dikalangan masyarakat luas. Aplikasi-apikasi yang sudah menerapkan kriptografi pada data teks pun sudah banyak dikembangkan. Beberapa penelitian di bidang kriptografi khususnya yang menggunakan algoritma DES yaitu Simulasi Aplikasi Algoritma DES Pada Transfer Data Uang Bank (Fitria, 2006) dan Simulasi Kerahasiaan / Keamanan Informasi Dengan Menggunakan Algoritma DES (Data Encryption Standard) (Indra Syahputra, 2009). 
Namun, pengimplementasian algoritma DES pada penelitian ini masih terbatas untuk file teks.

Selain file teks, file audio juga sangat perlu untuk disandikan terlebih-lebih file audio yang bersifat penting dan rahasia. Sebagai contoh yaitu file audio yang berisi rekaman instruksi perang atau strategi perang dan file audio yang berisi rekaman lagu untuk sebuah ajang kompetisi yang akan dikirim melalui internet. Contoh lainnya yaitu file audio yang berisi rekaman mengenai warisan yang harus disimpan dalam waktu tertentu dan file audio yang berisi rekaman pidato politik yang hanya boleh diketahui oleh internal partai tertentu. File-file audio tersebut sudah seharusnya dijaga kerahasiaannya. Sehingga, apabila file tersebut jatuh ke pihak yang tidak bertanggungjawab tidak akan memiliki makna yang berarti baginya. Salah satu cara untuk menjaga kerahasiaan file audio tersebut adalah dengan menggunakan aplikasi kriptografi, khususnya aplikasi kriptografi file audio.

\section{KAJIAN PUSTAKA}

\subsection{Kriptografi}

Kriptografi merupakan ilmu sekaligus seni untuk menjaga keamanan pesan (Cryptography is the art and science of keeping messages secure) (Rinaldi Munir, 2006), selain itu ada pengertian tentang kriptografi yaitu kriptografi merupakan ilmu yang mempelajari teknik-teknik matematika yang berhubungan dengan aspek keamanan informasi seperti kerahasiaan, integritas data, serta otentikasi (Rinaldi Munir, 2006). Kata "seni” di dalam definisi di atas maksdnya adalah mempunyai cara yang unik untuk merahasiakan pesan (kata "graphy” di dalam “cryptography” itu sendiri sudah menyiratkan sebuah seni). (Rinaldi Munir, 2006).

\subsection{Algoritma Kriptografi Data Encryption Standard (DES)}

Data Encryption Standard (DES) termasuk ke dalam sistem kriptografi simetri dan tergolong jenis cipher blok. DES merupakan algoritma enkripsi yang paling banyak dipakai di dunia, yang diadopsi oleh NIST (National Institute of Standards and Technology) sebagai standar pengolahan informasi federal AS. Secara umum DES terbagai menjadi tiga kelompok, yaitu pemrosesan kunci, enkripsi data 64 bit dan dekripsi data 64 bit (Dony Ariyus, 2008).

DES menggunakan algoritma yang sama untuk proses enkripsi dan dekripsi. Jika pada proses enkripsi urutan kunci internal yang digunakan adalah $K_{1}, K_{2}, \ldots, K_{16}$, maka pada proses dekripsi urutan kunci yang digunakan adalah $K_{16}, K_{15}, \ldots, K_{1}$. Dengan kata lain, algoritma yang digunakan untuk enkripsi dan dekripsi sebenarnya sama, hanya perbedaannya pada dekripsi penggunaan kunci internal yang terbalik. 
Skema Algoritma DES yang lebih rinci ditampilkan pada Gambar 1.

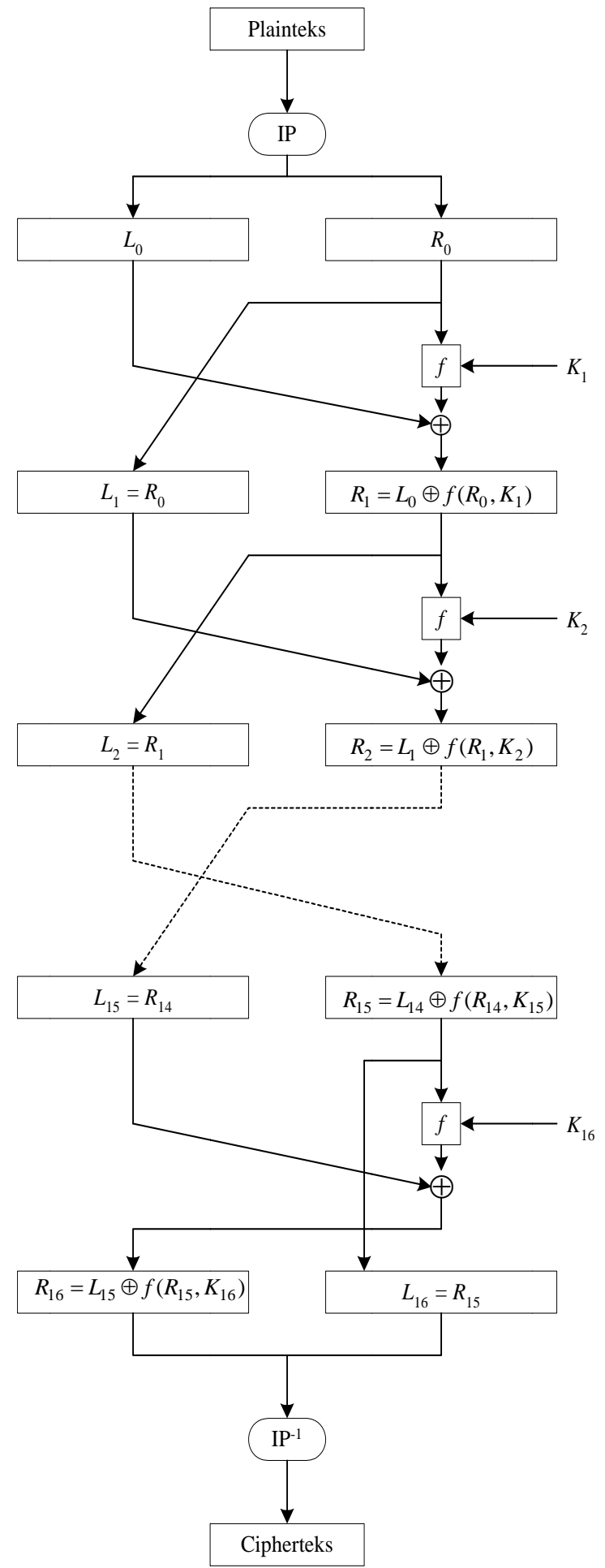

Gambar 1. Algoritma Data Encryption Standard (DES)

(Sumber: Rinaldi Munir, 2006) 


\subsection{File WAV}

Dalam teknologi perangkat lunak dikenal adanya file yang berekstensi WAV. File WAV ini merupakan file audio standar yang digunakan oleh Windows. File WAV ini memungkinkan suara direkam dalam berbagai kualitas, seperti 8-bit atau 16-bit samples dengan rate $11025 \mathrm{~Hz}, 22050 \mathrm{~Hz}$ atau $44100 \mathrm{~Hz}$. Untuk kualitas yang baik, yaitu: $44100 \mathrm{~Hz}$, 16-bit akan memakan kapasitas sekitar $150 \mathrm{~Kb}$ setiap detiknya. Suara yang berupa digital audio dalam file WAV disimpan dalam bentuk gelombang, karena itulah file ini memiliki ekstensi WAV. File WAV ini dapat dibuat dengan menggunakan berbagai program wave editor maupun wave recorder. Contoh wave recorder adalah Sound Recorder milik Windows atau Sound o'LE milik Soundblaster, sedangkan contoh wave editor adalah Goldwave, dan Coolwave. Struktur file WAV ditampilkan pada Gambar 2.

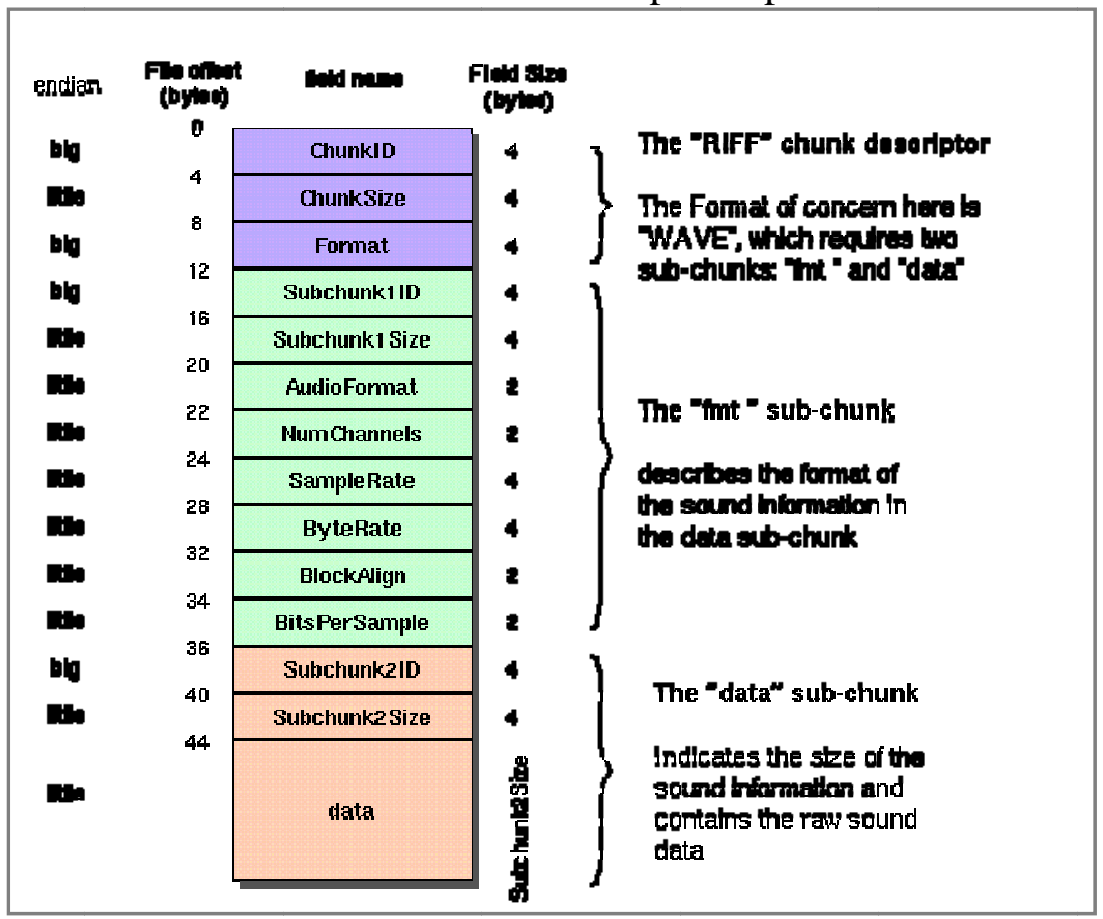

Gambar 2. The Canonical Wave File Format

(Sumber: http://ccrma.stanford.edu/courses/422/projects/waveFormat/)

\section{ANALISIS DAN PERANCANGAN}

\subsection{Analisis Perangkat Lunak}

\subsubsection{Kebutuhan Perangkat Lunak}

Perangkat lunak yang akan dibangun bernama AudioEnrcyptor. Adapun prosesproses yang dapat diimplementasikan oleh perangkat lunak AudioEnrcyptor, yaitu diantaranya a) membaca dan menyimpan file audio untuk dienkripsi ataupun untuk didekripsi, b) membentuk 16 internal key untuk digunakan pada proses enkripsi dan 
dekripsi dimana internal key dibentuk berdasarkan key yang diinputkan oleh user, c) melakukan enkripsi dan dekripsi file audio, d) merekam file audio dalam format WAV, dan e) memutar file audio yang akan dienkripsi dan didekripsi serta file audio yang telah direkam.

\subsubsection{Tujuan Pengembangan Perangkat Lunak}

Perangkar lunak AudioEncryptor merupakan perangkat lunak yang menerapakan algoritma Kriptografi DES untuk mengenkripsi file audio khususnya file audio dengan format WAV. AudioEncryptor diharapkan dapat membantu seseorang yang memiliki file audio yang bersifat penting dan rahasia tetap terjaga kerahasiaan informasi yang terkandung di dalamnya.

\subsubsection{Masukan dan Keluaran Perangkat Lunak}

Berdasarkan proses yang telah dijelaskan sebelumnya, perangkat lunak AudioEncryptor memiliki 4 proses utama yaitu record file audio, play file audio, enkripsi file audio, dan dekripsi file audio.

Masukan untuk proses record file audio adalah berupa gelombang suara yang dalam hal ini diambil dari kartu suara (sound card). Keluaran untuk proses ini adalah file audio dalam format wav. Masukan untuk proses play file audio adalah file audio dalam format wav, baik berupa file yang baru direkam pada proses record file audio atau file audio yang sudah tersimpan di data storage.. Keluaran dari proses play file audio adalah berupa suara yang dioutputkan pada speaker.

Masukan untuk proses enkripsi file audio adalah file audio asli yang akan dienkripsi dan masukkan berupa key untuk digunakan dalam proses enkripsi. Adapun keluaran dari proses ini adalah berupa file audio dengan sample data teracak tetapi tetap memiliki format yang sama dengan file audio asli. Sedangkan masukan untuk proses dekripsi adalah berupa file audio yang sudah dienkripsi sebelumnya dan key. Key yang dimasukkan ketika proses dekripsi harus sama dengan key yang dimasukkan ketika proses enkripsi. Keluaran dari proses dekripsi ini adalah file audio asli, yaitu sama dengan file audio sebelum dienkripsi.

\subsubsection{Model Fungsional}

Pada model fungsional perangkat lunak menjelaskan gambaran umum terhadap proses yang terjadi dalam perangkat lunak. Model fungsional dapat memberikan gambar terhadap proses yang terjadi antara perangkat lunak dengan pengguna luar (user). Interaksi antara perangkat lunak dan user dapat memberikan bentuk proses secara jelas yang terjadi pada perangkat lunak seperti masukan dan keluaran dari proses yang dikerjakan. Model fungsional dari perangkat lunak AudioEncryptor dideskripsikan menggunakan Unified Modeling Language (UML). User akan melakukan beberapa proses interaksi yang terdapat pada perangkat lunak seperti pada Gambar 3. 


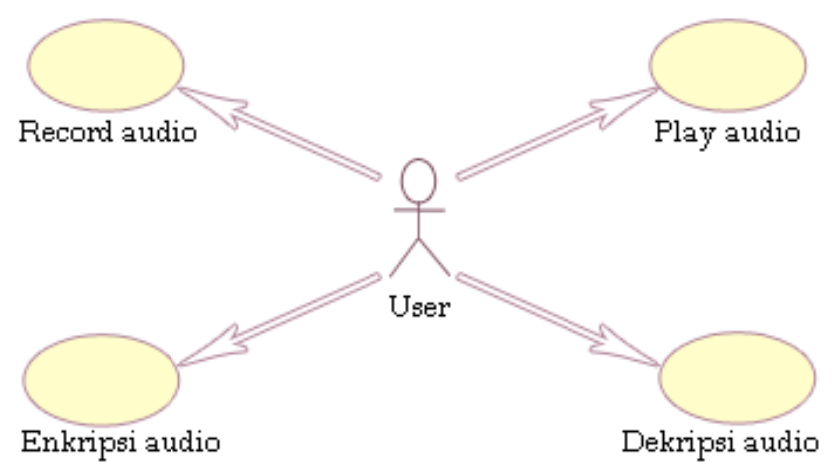

Gambar 3. Use Case Diagram Perangkat Lunak AudioEncryptor

\subsection{Perancangan Perangkat Lunak}

Pada perancangan perangkat lunak AudioEncryptor ini terdapat beberapa tahapan yang dilalui, yaitu batasan perancangan, perancangan arsitektur, perancangan struktur data, dan perancangan antar muka.

\subsubsection{Batasan Perancangan Perangkat Lunak}

Adapun batasan yang terdapat dalam perancangan perangkat lunak AudioEncryptor adalah sebagai berikut.

a) AudioEncryptor menyediakan fasilitas record, play, enkripsi, dan dekripsi file audio.

b) AudioEncryptor hanya dapat merekam, memutar, mengenkripsi dan mendekripsi file audio dengan format WAV.

c) Besarnya ukuran file audio yang dapat direkam, diputar, dienkripsi dan didekripsi tergantung dari besarnya memori yang tersedia pada komputer user.

\subsubsection{Perancangan Arsitektur Perangkat Lunak}

Pada perancangan arsitektur perangkat lunak menggambarkan bagian-bagian modul, struktur ketergantungan antar modul, dan hubungan antar modul dari perangkat lunak yang dibangun.

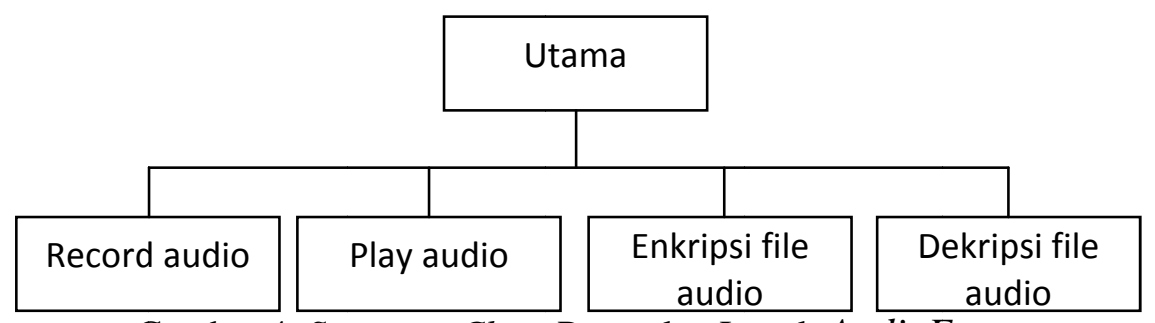

Gambar 4. Structure Chart Perangkat Lunak AudioEncryptor

Pada Perangkat lunak AudioEncryptor terdapat 6 Class utama yang digunakan untuk merekam, memutar, mengenkripsi, dan mendekripsi file audio.

a) Class Main, adalah class untuk pembuatan antar muka perangkat lunak (GUI). 
b) Class recordAudio, adalah class untuk merekam suara dan menyimpannya dalam format WAV.

c) Class playAudio, adalaha class untuk memutar file audio khusus file audio dengan format WAV.

d) Class wavIO, adalah class untuk membaca dan menyimpan file audio.

e) Class internalKey, adalah class untuk meng-generate 16 sub-key yang akan digunakan pada proses enkripsi.

f) Class enkripsiByDES, adalah class yang menangani proses enkripsi dan dekripsi.

\subsubsection{Perancangan Struktur Data}

Perangkat lunak ini dibangun pada area pemrograman berorientasi objek, oleh karena itu struktur data yang digunakan adalah objek dan jenis tipe data primitif lainnya. Struktur data utama yang sering digunakan dalam perangkat lunak AudioEncryptor ini adalah struktur data untuk objek String, integer, dan array byte. Struktur data untuk objek String berfungsi untuk melakukan manipulasi nilai bit yang digunakan untuk mengubah sample data file audio menjadi nilai biner. Nilai biner yang terdiri dari nilai 0 dan 1 dibentuk menggunakan objek String dan untuk memanipulasinya, menggunakan operasi biner yang disesuikan oleh operasi pada objek String. Struktur data untuk objek integer berfungsi untuk menyimpan size dari sebuah file audio. Sedangkan struktur data untuk objek array byte berfungsi untuk menyimpan nilai sample data dari sebuah file audio.

Selain struktur data tersebut, perangkat lunak AudioEncryptor juga memanfaatkan struktur data lain seperti objek file karena AudioEncryptor pada prinsipnya bekerja pada level operasi file seperti membaca, mengelola, dan menyimpan file. Sedangkan struktur data pendukung yang lainnya yaitu objek Image dan Icon. Objek Image dan Icon ini digunakan untuk memperindah tampilan GUI dari perangkat lunak AudioEncryptor.

\subsubsection{Perancangan Antarmuka}

Antarmuka perangkat lunak terdiri atas Form menu utama sebagai berikut.

\begin{tabular}{|l|l|}
\hline File About Help & \\
\hline & Aplication Title \\
\hline Record audio & \\
\hline Play audio & \\
\hline Encrypt audio & \\
\hline Decrypt audio & \\
\hline
\end{tabular}

Gambar 5. Form Utama Aplikasi Kriptografi AudioEncryptor

\section{IMPLEMENTASI PERANGKAT LUNAK}


Dari analisis dan perancangan yang telah dilakukan, langkah selanjutnya adalah melakukan implementasi perangkat lunak.

\subsection{Implementasi Modul}

Tabel 1. Tabel Pemetaan Terhadap Class Implementasi

\begin{tabular}{|l|l|l|}
\hline \multicolumn{1}{|c|}{$\begin{array}{c}\text { Class } \\
\text { Perancangan }\end{array}$} & \multicolumn{1}{c|}{$\begin{array}{c}\text { Class } \\
\text { Implementasi }\end{array}$} & \multicolumn{1}{c|}{\begin{tabular}{c}
\multicolumn{1}{c|}{ Penjelasan } \\
Class Implementasi
\end{tabular}} \\
\hline Main & Main.java & $\begin{array}{l}\text { Class yang berisi method untuk membuat } \\
\text { GUI. }\end{array}$ \\
\hline recordAudio & recordAudio.java & $\begin{array}{l}\text { Class yang berisi method untuk merekam } \\
\text { audio. }\end{array}$ \\
\hline playAudio & playAudio.java & $\begin{array}{l}\text { Class yang berisi method untuk memutar } \\
\text { audio. }\end{array}$ \\
\hline wavIO & wavIO.java & $\begin{array}{l}\text { Class yang berisi method untuk baca dan } \\
\text { simpan file audio. }\end{array}$ \\
\hline internalKey & internalKey.java & $\begin{array}{l}\text { Class yang berisi method untuk meng- } \\
\text { generate 16 sub-key. }\end{array}$ \\
\hline enkripsiByDES & enkripsiByDES.java & $\begin{array}{l}\text { Class yang berisi method untuk } \\
\text { menangani proses enkripsi dan dekripsi. }\end{array}$ \\
\hline
\end{tabular}

\subsection{Implementasi Struktur Data}

Sesuai dengan rancangan struktur data yang telah dibuat, dapat diimplementasikan struktur data pada lingkungan pengembangan perangkat lunak. Perangkat lunak ini dibangun berdasarkan orientasi objek sesuai dengan lingkungan pengembangan perangkat lunak yaitu Java. Dalam java, tipe data dikelompokkan menjadi dua jenis tipe data, yaitu tipe data primitif dan tipe data referensi. Berdasarkan lingkungan pengembangan tersebut, struktur data yang diimplementasikan merupakan struktur data yang berupa tipe data primitif seperti tipe data integer, boolean, dan long serta penggunaan tipe data referensi yang berupa objek yang telah tersedia seperti objek String dan objek array.

Objek String digunakan untuk mengubah dan mengolah bilangan biner yang digunakan ketika enkripsi dan dekripsi file audio. Objek array yang digunakan adalah integer dan array byte. Struktur data integer berfungsi untuk menyimpan size dari sebuah file audio. Sedangkan objek array byte digunakan untuk menampung nilai sample data dari sebuah file audio.

\subsection{Implementasi Antarmuka}

Rancangan layar antarmuka perangkat lunak AudioEncryptor diimplementasikan menggunakan class-class yang terdapat pada package java.awt dan java.swing. Implementasi layar antarmuka perangkat lunak AudioEncryptor ini menggunakan NetBeans IDE 6.0.1 sebagai editor. Untuk implementasi antarmuka Form Menu Utama dapat dilihat pada Gambar 6. 


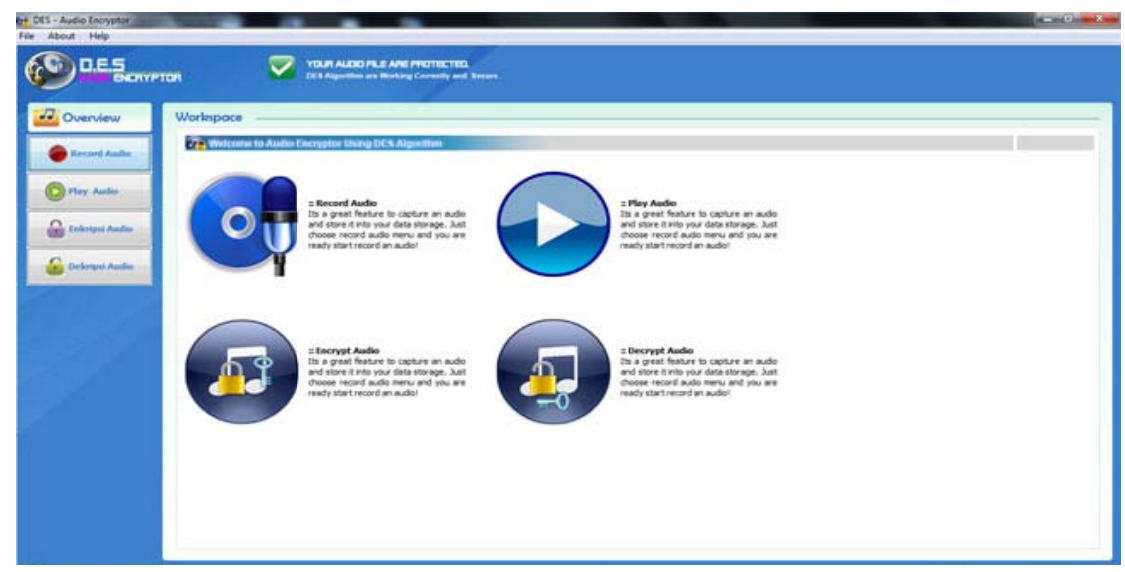

Gambar 6. Implementasi Layar Antarmuka Form Menu Utama

\section{PENUTUP}

Berdasarkan penelitian yang telah dilakukan yaitu "Pengembangan Aplikasi Kriptografi File Audio dengan Algoritma Data Encryption Standard (DES)” adapun simpulan yang didapat antara lain.

a) Rancangan sistem aplikasi kriptografi file audio digambarkan menggunakan Unified Modeling Language (UML) yang dapat menggambarkan arus data dalam sistem dengan jelas dan sebagai alat dokumentasi yang baik. Penggambaran UML Pengembangan Aplikasi Kriptografi File Audio dengan Algoritma DES terdiri dari usecase diagram, activity diagram, sequence diagran, dan VOPC diagram.

b) Implementasi Algoritma DES pada aplikasi kriptografi file audio menghasilkan sebuah perangkat lunak yang mampu mengenkripsi file audio dengan size file audio hasil enkripsi dan file audio hasil dekripsi yang tetap sama dengan size file audio sebelum dienkripsi. Suara yang dikeluarkan oleh file audio hasil enkripsi tidak sama dengan suara sebenarnya, sehingga kerahasiaan informasi yang terkandung dalam file audio yang sudah dienkripsi sangat aman.

\section{DAFTAR PUSTAKA}

Ariyus, Dony. 2008. Pengantar Ilmu Kriptografi Teori, Analisis, dan Implementasi. Yogyakarta: CV. Andi Offset.

Fitria, Faiz Sungkar. 2006. "Simulasi Aplikasi Algoritma Des Pada Transfer Data Uang Bank”. Jurnal Informatika, Vol.6, No.1. STMIK Darmajaya.

Hermawan, Benny. 2004. Menguasai Java 2 \& Object Oriented Programming. Yogyakarta: Andi Publisher.

Indra Syahputra. 2009. Simulasi Kerahasiaan / Keamanan Informasi Dengan Menggunakan Algoritma DES (Data Encryption Standard). Skripsi (tidak diterbitkan). Universitas Sumatera Utara. 
Rasyid, Muhamad Fajrin. 2009. "Kriptografi Audio dengan Teknik Interferensi Data Non Biner”. http://digilib.itb.ac.id (diakses tanggal 20 Desember 2010).

Rinaldi Munir. 2006. "Bahan Kuliah 1, IF 5054 Kriptografi Pengantar Kriptografi”. http://www.informatika.org/ rinaldi/Kriptografi/2006-2007/kripto2006.htm (diakses tanggal 20 Desember 2010).

Rinaldi Munir. 2006. "Bahan Kuliah, IF 5054 Cipher Block". http://www.informatika.org/ rinaldi/Kriptografi/2006-2007/kripto2006.htm (diakses tanggal 20 Desember 2010).

Rinaldi Munir. 2006. "Data Encryption Standard (DES)”. http://kur2003.if.itb.ac.id/file/DES.doc (diakses tanggal 20 Desember 2010).

Scott Wilson. 2003. "WAVE PCM soundfile format”. https://ccrma.stanford.edu/courses/422/projects/WaveFormat/ (diakses tanggal 4 Desember 2010).

William Stallings. 2003. Network Security Essentials - Appications and Standard. New Jersey: Prentice Hall.

William Wilson. 2007. “Steganography”. http://www.dreamincode.net/ forums/topic/27950-steganography (diakses tanggal 20 Desember 2010). 